\title{
Undergraduate Dissertations in a Department of Architecture
}

\author{
Dr Ombretta Romice, Lecturer \\ Department of Architecture, University of Strathclyde \\ Dr Paul Yaneske, Senior Lecturer \\ Department of Architecture, University of Strathclyde \\ 131 Rottenrow, Glasgow G4 ONG
}

\section{Abstract}

Undergraduate academic writing in a Department of Architecture offers opportunities as well as challenges. To students, it can be a source of independent research and learning, enriching their development as architects and critics of the built environment; at the same time it can be an obstacle, a perceived impediment to design work. To staff, it can be a chance to share their research interest with colleagues and students, so enriching exchange and debate; it can also be time consuming and not clearly relevant to the formation of a professional. This case study argues that a change in attitude towards the objectives of the dissertation, coupled with careful consideration of its curriculum, can enhance the role that undergraduate academic writing plays in a School of Architecture, extending its benefits to the development of research and design agendas.

Keywords: Dissertation, Curriculum Design, Research Methods 


\section{Good Practice Points}

- $\quad$ Clearly define the aims and nature of the dissertation so that both staff and students understand its role within the architectural curriculum and its value in relationship to the other classes and courses.

- $\quad$ Design the delivery structure for the dissertation with equal clarity in terms of the supporting framework for both students and supervisors introductory seminars, groups supervision, deadlines etc. - needed to achieve the quality defined above. The same rigour expected from students must be expected from staff!

- $\quad$ Ensure dissertations are integrated into the curriculum by reinforcing links with classes in other years and in the same year. In this way, the dissertation becomes the culmination of the cultural and critical training that students receive across the board. This should be done in conjunction with the Department Course Management Group.

- $\quad$ Clarify at the outset the outcomes students are expected to produce, the criteria by which they will be assessed and the rules and procedures for the dissertation during the year. Make sure that staff have the same understanding.

- Make contact with departments that are specialised or involved in teaching and learning; they can offer great insight into the educational experience of writing dissertations and undertaking research, pointing out areas to reinforce and/or support through training, as well as identifying issues in management and organisation.

- Do not limit supervision to one supervisor. Create thematic groups, which gather supervisors and students around similar research topics. This widens the support that supervisors can give students, and reinforces the quality of arguments and ideas.

- $\quad$ Arrange for students to exchange dissertations among themselves because this adds an extra layer of control, revision and accuracy to the work, while reducing the burden on supervisors.

- $\quad$ Assure comparability between dissertations, both during their progress and at the final marking. This is a function that can be carried out by a Dissertation Convenor whereby he/she should read a significant sample and make sure that the criteria of assessment have been respected by all supervisors and research groups. 


\section{Background - context, problem tackled and aims}

Ombretta Romice, as Dissertation Convenor, has coordinated the honours year dissertation programme in the Department of Architecture at Strathclyde for three years, during which time Paul Yaneske has been the year convenor and chair of the departmental Learning and Teaching Group. At Strathclyde, students can graduate with a Pass degree in architectural studies after Year 3, or an Honours degree after Year 4 (i.e. after a total of four years full time academic study); the first professional training year is normally taken as a year out placement after Year 3. The Dissertation is part of the common curriculum for both Honours year students and for students entering directly into the Department onto the first year of the Master of Architecture (MArch) programme. In both cases, successful completion of the curriculum allows progression into Year 5, the year of MArch graduation. The students are encouraged to develop the Dissertation as an area of personal interest, which can be the foundation for further work in the fifth year as this is organised in thematic streams - Advanced Architectural Design, Architectural Computing and Urban Design. The second professional year is taken after Year 5. At the time the authors started working on Dissertations, these had just been reintroduced after a number of years when they had not been compulsory and were in a very poor state. There was no support/preparation for students or staff, the choice of topics was too dependent on student preference and there was very little guidance on criteria of evaluation or quality benchmarks. Final evaluation standards were hard to characterise within uniform parameters and student progress over the year depended too heavily on individuals.

Criticism from external examiners and from internal review processes made it clear that the meaning and task of writing dissertations, together with the procedural framework and evaluation criteria, had to be clarified. It was decided that a dissertation had to be a rigorously critical, written piece of work of around 8000 words on a topic selected by the student in agreement with the supervising member of staff and the Dissertation Convenor; that its content should be drawn from a study of literature in a chosen area, fieldwork and/or experimental investigation, followed by informed evaluation and/or speculation. Comparable rigour had to be introduced into the support (preparation and supervision) processes. Needless to say, the task of instilling rigour to both contents and process has not been an easy one. With the dissertation initially counting for one sixth of the honours year credit total and then rising to a quarter the following year, it was important to redefine the process to make it more accountable and controllable.

In a typical Department of Architecture, and Strathclyde was a good example, greater emphasis is generally placed upon the design and studio culture than upon written/academic work; classes such as history and technology tend to be seen as subservient to design (with notable exceptions such as the Bartlett, Oxford Brookes University and Cambridge University). The main difficulty was, therefore, to instil the understanding that a written piece of work bears a weight comparable to design work because design and studio are generally more highly regarded than other classes. It 
takes time to change this attitude and both staff and students have to be persuaded. If staff acknowledge the importance of written work, students tend to follow their lead and recognise it as well. To succeed, staff need to share an ethos of interest and rigour in research as an integral and informative part of the design process. Where this does not happen, the quality of the supervision and, hence, the quality of student work will depend on individual effort: this cannot guarantee systematic control of quality.

\section{Setting up the curriculum}

The first step in reassessing dissertations was to acknowledge that they had to be managed with rigour and perseverance and that they could no longer be considered as an isolated piece of work in the curriculum, but rather as the culmination of the cultural and critical training that students received across the board. The long-term plan was, therefore, to make more explicit the link between the dissertation and the Architectural History and Theory classes (AHT), which take place in 1st, 2nd and 3rd year, and to Optional classes (delivered by staff on their specific area of investigation) which take place in the honours $\left(4^{\text {th }}\right)$ year and which, by offering an insight into staff's own research, can stimulate students' own research interests. This process is ongoing and, after three years, is now showing results. AHT was revised four years ago to emphasise research and develop a positive attitude towards reading and writing. Students undertaking the dissertation over the past academic year are the first to have benefited from all three years of the revised course. On the other hand, selection of the honours year optional classes by students depends increasingly on the affinity of their own research interests with those of the staff. The optional classes are also timetabled so that their input takes place before the main dissertation work starts.

Another important step in designing the dissertation curriculum was to clarify what outcomes students needed to produce by the end of the process. Advantage was taken of the strong and continuing collaboration between the Department of Architecture and the Centre for Academic Practice (CAP) at the University of Strathclyde, which is a support department to academic departments. CAP was extremely useful in offering insight into the creative writing process and how it can enhance the creative design process; this knowledge comes from their pedagogical background and resulted in much saving of time which would otherwise have been spent on trial and error attempts. CAP is also experienced in giving students advice on time management and provided an induction to students on this important issue in the context of the dissertation. In conversation with CAP, the authors were lead to the realisation that, although students are well used to individual studio work which develops through weekly tutorials by their final year, they have little experience in carrying out a demanding written exercise which has to be balanced against other competing tasks. In particular, unless counteracted, students tend to separate the research and literature review phase from the writing up phase, thereby leaving too little time for the latter and for the progressive development of the two together. 
What follows is a description of dissertations as they are now delivered after three years of fine-tuning; it is fair to say that the Department is changing its attitude towards the dissertation as the following three facts demonstrate: it has changed the value of dissertations to one quarter of the honours degree credit requirement; dissertations are being submitted for national competitions; and a final year prize, awarded in conjunction with design prizes, has been established.

\section{Implementation - innovative practices, student induction, resources}

Through the medium of the dissertation, students are required to demonstrate the ability to:

- $\quad$ Research and investigate existing bodies of knowledge that provide the student with new information related to architecture;

- $\quad$ Select, identify, incorporate and acknowledge pertinent material drawn from others in the submission;

- Make assumptions, develop an argument and demonstrate their position with evidence;

- $\quad$ Communicate their position through an appropriate combination of verbal, written, graphic and visual means;

- $\quad$ Critically summarise the evidence gathered and draw conclusions.

A Research Unit may further refine these competencies to give a more specific context to reflect the ethos of its research programme.

Since expectations about the standard of student work have grown considerably over the past three years; a delivery framework was set up to prepare and assist students in the conception, development and delivery of their work. Though stress is placed on the dissertation as the chance for the student to carry out independent work, a rich supporting environment for both students and supervisors is fundamental, especially when the aim is to encourage an undergraduate research culture. Writing a Dissertation comprises:

- $\quad$ Five introductory seminars, which give students the basis on how to conduct research, how to find sources, how to refer and acknowledge other people's work and reference according to University standards, how to pick a topic and establish a working relationship with the supervisor and an understanding of the assessment criteria. Some of these seminars have been designed in cooperation with CAP so that they are direct and practical, blending notions of creativity and personal development with others of organisation and management. The departmental librarian offers very practical tutorials about online bibliographical research, encouraging students to use the numerous 
resources that the University offers; again, this is a resource much appreciated by students (and staff).

- $\quad$ Supervision by an individual member of staff who is also part of a departmental research group and selected according to the topic. This guarantees: 1) a broader choice for students, who can find and refine a topic with the help of a group of staff and peers; 2) the possibility for a more critical environment in terms of feedback and points of view; 3 ) the help of several staff and their specialism in serving both students and other staff in writing and supervising dissertations.

- $\quad$ Regular group seminars run by students and research groups where every student presents his/her progress and all the supervisors of the group and students give feedback.

- $\quad$ Regular meetings between students and supervisors for individual tutoring sessions where a log sheet is kept recording the aims of the meeting and the tasks for the following meeting.

- $\quad$ Students exchanging dissertations with each other on two occasions for peer review and proof-reading; this happens in relation to one of the two interim submissions (500 and 3000 words) and for the final draft.

- $\quad$ Assessment based on students demonstrating achievement of the learning outcomes listed above which is carried out on both interim and final submissions. These criteria are made clear to both students and staff from day one and have been defined and implemented over a period of 3 years with the help of colleagues, external examiners and students.

The introductory seminars are very useful for students as over a period of 5 weeks, they are presented weekly with all the hurdles they will have to face during the process. The seminars cover selecting a topic, establishing a working relation with the supervisor, how the work is assessed, what is research and how to find sources and material, plagiarism and how to produce the document in its different phases - the 3000 word submission (a work-in-progress structured document which contains the substance of the research but is not complete yet) and the final document. These seminars include all the relevant information that has been found to be useful in setting up the procedures for the dissertation and present students with the problems, questions and other relevant information gained from previous experience. Moreover, at the beginning of the year, students receive a very complete and detailed handbook, which contains the aims, objectives, learning outcomes, working procedures, a description of each research group they can join, the criteria of assessment, the marking procedure and the timetable. 


\section{Assessment Methods}

Assessment throughout the dissertation process is fundamental; students rely on it to progress and it must, therefore, be scheduled with other classes/studio and academic breaks in mind. Also, it must relate precisely to the learning outcomes listed above which are made clear and public from day one. Students are assessed through one-toone supervision, group seminars where each student regularly presents his/her progress, interim submissions (500 and 3000 word) and a final submission. Students always receive written feedback on the 500 and 3000 word interim submissions. This feedback is produced by the supervisor and conflates the views of the supervisor and the convenor who, in always reading and assessing every submission, guarantees a balanced view across the year. When necessary, the Convenor calls meetings with students and supervisors to discuss problems/delays.

Each final submission is marked against the stated competencies by the supervising member of staff and normally, one other academic staff member of the associated Research Unit, in accordance with the general framework of the Marking and Assessment System, as published in the Departmental Undergraduate Handbook. It is the responsibility of the supervisor to submit agreed marks to the Dissertation Convenor, or to advise the Dissertation Convenor of any disagreement. All final submissions are also independently assessed by the Dissertation Convenor; the Head of Department reads a selected sample prepared by the Dissertation Convenor. The final mark is decided by a panel consisting of the Supervisor (the individual member of staff providing the student supervision for the Dissertation under consideration), a Second Marker (drawn from the staff of the research group providing the supervision), the Dissertation Convenor and the Head of Department (where involved in assessment). Where disagreement over the final mark persists, the panel appoints a third marker from the academic staff to provide a further independent assessment. In the light of experience, the Department has agreed that this review process, involving supervisors, research units and Convenor (and Head of Department when necessary) is good for the exchange of ideas and confrontation of methodologies and attitudes to research.

The assessment and marking procedure is thorough and carried out in stages; the fact that the Convenor reads and evaluates each dissertation assures comparability between students supervised by different Research Units and guarantees an overall view on the progress of each student. In fact, a file is kept on each student and his/her progress is constantly monitored by the Dissertation Convenor.

Each successive year, the marking discrepancies between individual supervisors, research units and Convenor have diminished. At the beginning, when the assessment criteria were not as clear and explicit, it was difficult to overcome marking discrepancies in that staff tended to feel protective of their own mark and student, and requesting a justification for their overall assessment was often taken contentiously and personally. With clear criteria, which are progressively assessed during the 
development of the dissertation, staff feel more comfortable in sharing evaluations and opinions, and even disagreements can be discussed and analysed. Individual criteria are used as a guide during the discussion, with the result that those who read the work express their opinion on each and come to agreement with no difficulty.

Feedback is also sought from students on their experience in writing a dissertation, on the quality of supervision, and on the organisation of the procedure during the year. Comments are anonymous but in depth and have revealed that students appreciate the organised and reliable overall setting and are, in general, satisfied with the level of induction they receive. They generally consider the dissertation as challenging and intimidating but worthwhile. Nevertheless, there has been criticism of the effectiveness of individual supervisors which has indicated clear characteristics that the student would expect from them: he/she should be severe, precise, clear, consistent and time conscious, capitalising on meetings and deadlines. Needless to say, that this is the reason why the Department is investing in both student and staff training.

\section{Costs/resources}

The Department of Architecture at Strathclyde is very committed to teaching and learning, with members of staff involved in the study and research of theories, procedures and techniques to enhance student experience. The involvement of the departmental Learning and Teaching Group through Paul Yaneske, together with external examiners, CAP, Ombretta Romice's personal experience in implementing the dissertation and producing a doctoral thesis and the Department's support for the ambition of increasing the role and accountability of dissertations, have been the main resources used to reach this stage. Texts such as: Borden \& Ruedi. 2000.

Dissertation: An Architecture Student's Handbook. Oxford: Butterworth-Heinemann have also provided a practical and more general resource.

Schemes such as those offering induction and training to new Lecturers and Tutors are also useful, even if they do not devote specific sessions to dissertations, they always deal with assignments, individual and group tutorials, seminar teaching, giving feedback, recording students' progress and student personal development. At Strathclyde, new members of staff must undertake a three-day seminar organised by the CAP.

The series of Dissertation seminars which was developed with CAP is now well established and every year improved to include the experiences of the previous session. We now have a substantial Dissertation Handbook that documents the process for both students and staff and is distributed to both at the beginning of the course. In addition a fully codified Internal Verification Procedure describes procedures and codes of conduct, again for staff, students and also external examiners, as part of the Department's Teaching Quality Assurance (TQA). The Internal Verification procedure for Dissertation has been the prototype for the development of further TQA procedures in the Department. 


\section{Considerations - benefits and enablers, conclusions}

Working with clear rules, procedures and criteria helps students programme the work and understand what the process involves. This encourages them to become independent and address topics of research personally and critically. Over the past three years dissertations have matured and students have become more engaged. Joining research groups also exposes students to a broad range of innovative research produced by departmental staff, and has helped them in establishing contact with key figures in their area of interest.

The task of setting up the dissertation procedure from scratch has been interesting in defining learning objectives and outcomes, devising procedures to achieve them and developing practices amongst staff and students that could meet these requirements. Perhaps the most interesting aspect has arisen from the need to ensure equality of assessment demands whilst acknowledging the difference in requirements and agendas between the various research units within the Department. The new challenge we are currently undertaking is to open up the nature and range of dissertations offered to accommodate students with disabilities in writing, reading and researching, or simply to better respond to students who might want to produce a critical work using media different than the written word. The current handbook already offers this possibility to students with disabilities and we are still working on guaranteeing comparability between products of a different nature.

It is no surprise that everybody involved in the process has had to develop new working procedures. The role of the Convenor is important: it has to assure that both students and staff respect deadlines, adopt the criteria recommended and are active in the research groups. Coordinating around 15 staff and an average of 35 students each year has required strict organisation and scheduling. The initial seminars helped clarify procedures and learning objectives to both students and staff and it is paramount that both attend them. The role of supervisors has also been challenged: having to respect guidelines and procedures has been a struggle in some cases, but it is now possible to offer a series of guidance or advisory notes for supervision at the start of each session. For example, supervisors receive advice on "What is supervision; its basics and procedures; how to tailor support to students' needs; how to make best use of supervisors' expertise; how to conduct individual tutorials and getting the most out of each meeting; how to help students organise their workload during the year". This guidance has just been produced and issued to all staff.

The research group seminars, in bringing together staff and students sharing an interest on a specific area, increase the competencies available, add to the discussion and can guarantee quality. Staff appreciate the seminars because they open up the debate and allow new ideas to be brought to the table; generally staff do not feel threatened because they are familiar with the work and research technique of colleagues within the group. This contributes to the development of a nonconfrontational and supportive atmosphere. Student feedback was positive on the 
seminars for several reasons; they are not considered as a formal assessment but as always providing rich feedback; they expose students to other students' work affording the opportunity for personal self-criticism; they are regarded as a good benchmark (a multiple opinion) that guarantees the quality of their work during development. The only criticism had to do with the fact that these seminars did not run systematically during the year but had to be accommodated within almost full timetables. From 2004/05, seminars will be included in the timetable from the start of the session. Nevertheless, it is up to the year and dissertation convenors and the studio leader to work out an arrangement which respects individual commitments. Effective group seminars do not necessarily have to be seen as an extra load on members of staff: if properly used they could reduce the number and intensity of individual tutorials.

Without forethought, dissertations can easily become a burdensome experience for supervisors, for example, with students extending their demands from guidance and feedback to proof-reading. To avoid this, it was decided to share this responsibility with students where possible. One useful practice is to have students exchange dissertations with each other which enables them to learn about the working methods and interests of their peers, encourages criticism and debate amongst themselves and allows the work to be checked before the supervisor sees it. There are two occasions on which this happens; at the submission of the 3000 words interim work and at the submission of the final document. This procedure is especially useful when students are able to benchmark their dissertation against work of good quality; they can be fairly critical towards each other and the process of discovering faults or good practices in the work of others is an effective feedback for personal performance. However, students whose work was generally good and complete often had to be encouraged to exchange work with students who were having difficulties, for instance, in writing, structure or completion. Consequently, staff must be available to offer extra support in reading texts when needed.

One last crucial condition for the success of the dissertation refers to its timetabling in relationship to other classes, submission deadlines and workload in general. Dissertations generally require six to eight months to complete, but time is used differently over this period. Research periods do not need to be concentrated and can spread across a few months, whereas writing up periods need more concentrated time. It is therefore important to carefully orchestrate the timetabling of the dissertation in order to respect and acknowledge the workload of other classes, especially the design studio. In this Department, the scheduling of the dissertation and studio offers 2 windows of 2 weeks duration each, when the studio has a reduced load in comparison to the dissertation hand-ins and vice versa. This works well, is appreciated by students and prevents disruptive overlapping.

The above noted dissertation procedures have now been reviewed for four years by external examiners who have offered critical but very constructive feedback. One examiner in particular, the late Dr Catherine Cooke, a renowned scholar, strongly 
believed in the role of writing and researching for the profession and spent a substantial amount of time in reviewing the Department's practices and procedures, offering hard but extremely constructive criticism over a period of three years. The value and role of dissertations is no longer questioned; the procedures currently in place should allow this role to develop through the years and facilitate the contribution of the dissertation to architectural education.

In summary, recommendations for best practice are as follows:

1. Clearly define the aims and nature of the dissertation so that both staff and students understand its role within the architectural curriculum and its value in relationship to the other classes and courses.

2. Design the delivery structure for the dissertation with equal clarity in terms of the supporting framework for both students and supervisors - introductory seminars, groups supervision, deadlines etc. - needed to achieve the quality defined in 1 . The same rigour expected from students must be expected from staff!

3. Ensure dissertations are integrated into the curriculum by reinforcing links with classes in other years and in the same year. In this way, the dissertation becomes the culmination of the cultural and critical training that students receive across the board. This should be done in conjunction with the Department Course Management Group.

4. Clarify at the outset the outcomes students are expected to produce, the criteria by which they will be assessed and the rules and procedures for the dissertation during the year. Make sure that staff have the same understanding.

5. Make contact with departments that are specialised or involved in teaching and learning; they can offer great insight into the educational experience of writing dissertations and undertaking research, pointing out areas to reinforce and/or support through training, as well as identifying issues in management and organisation.

6. Do not limit supervision to one supervisor. Create thematic groups, which gather supervisors and students around similar research topics. This widens the support that supervisors can give students, and reinforces the quality of arguments and ideas.

7. Arrange for students to exchange dissertations among themselves because this adds an extra layer of control, revision and accuracy to the work, while reducing the burden on supervisors. 
O. Romice and P. Yaneske: Undergraduate Dissertations in a Department of Architecture

8. Assure comparability between dissertations, both during their progress and at the final marking. This is a function that can be carried out by a Dissertation Convenor whereby he/she should read a significant sample and make sure that the criteria of assessment have been respected by all supervisors and research groups. 